\title{
THE DETECTION OF LINKED EPISTATIC GENES IN DROSOPHILA
}

\author{
R. J. KILLICK* \\ Department of Genetics, University of Birmingham
}

Received 1.viii.70

\section{InTRODUGTION}

Estimates of additive and dominance gene effects from the means of generations derived from crosses between two inbred lines are unaffected by linkage, but estimates of epistatic parameters-and hence the efficiency of scaling tests-are conditioned by linkage (van der Veen, 1959). Using a model in which linkage was included in the digenic epistatic parameters, Jinks and Perkins (1969) were able to describe the variation between 21 generation means for final height in Nicotiana rustica, though when linkage was excluded, neither a model containing digenic interactions nor one containing trigenic interactions fitted the data. From the probability levels given in their paper it is clear that the inclusion of linkage in the model may considerably improve the accuracy of such an analysis. The models of van der Veen and of Jinks and Perkins assume that recombination between genes is the same in both sexes. There are, however, a number of species, of which Drosophila is the most widely known, in which the male meiosis is achiasmate and hence intrachromosomal genic recombination occurs only in the female. In this paper the interrelations of linkage and epistasis in such species are considered.

\section{Notation}

When digenic interactions are allowed for, six parameters are required to specify the variation between generation means. These are:

$m$ = the midparent

$d_{a}=$ the additive gene effect of the ath locus

$h_{a}=$ the dominance effect of the ath locus

$i_{a b}=$ the additive $\times$ additive interaction between the $a$ th and $b$ th locus.

$j_{a / b}=$ the interaction of the $a$ th locus when homozygous with the $b$ th locus when heterozygous.

A second such interaction, $j_{b / a}$, will also exist but is frequently assumed to be of the same size as $j_{a / b}$, and only one $j$ parameter is specified.

$l_{a b}=$ the dominance $\times$ dominance interaction between the $a$ th and $b$ th locus.

All expectations will be given in the $\mathrm{F} \infty$ metric for the reasons discussed by van der Veen (1959). In the description of a cross the female parent is designated first. Thus $F_{1} \times P_{1}$ represents a first back-cross $\left(\mathrm{B}_{1}\right)$ using the $\mathrm{F}_{1}$ as female parent and $\mathrm{P}_{1}$ as male parent. In more complicated crosses

* Present address: Scottish Plant Breeding Station, Pentlandfield, Roslin, Mid lothian. 
parentheses are used to indicate earlier matings, the progeny of which are parents in the later cross. Thus $\mathrm{P}_{1} \times\left(\mathrm{F}_{1} \times \mathrm{P}_{2}\right)$ is a second back-cross $\left(\mathrm{B}_{21}\right)$ the ancestry of which is as follows. A female $F_{1}$ was crossed to a male of line $2\left(\mathrm{P}_{2}\right)$ making a first back-cross $\left(\mathrm{B}_{2}\right.$ here written as $\left.\left(\mathrm{F}_{1} \times \mathrm{P}_{2}\right)\right)$. A male of this first back-cross was crossed to a female of line $\mathrm{I}\left(\mathrm{P}_{1}\right)$ making the second back-cross. With inbred lines there is no difference between reciprocal $F_{1} s$ in the absence of sex linkage or maternal effects, hence there is no need to specify the direction of the $\mathrm{F}_{1}$ crosses. It is assumed $\mathrm{P}_{1}$ has a larger mean than $\mathrm{P}_{2}$ and that the genes are in coupling, i.e. $\mathrm{P}_{1}$ is $\frac{A B}{A B}$ and $\mathrm{P}_{2}$ is $\frac{a b}{a b}$.

The recombination fraction is written as $p$.

\section{THEORY}

(i) Generation means

Table 1 shows the expected means of parents, $F_{1}, F_{2}$ (which in sexually dimorphic species where selfing is impossible is created by sib mating the $F_{1}$ ), $F_{2}$ bip $\left(F_{2}\right.$ individuals sib mated), first and second back-crosses, first back-crosses sib mated ( $B_{1}$ bip, $B_{2}$ bip) and generations derived by crossing the $F_{1}$ and the parents to the $F_{2}$ and the first back-crosses to the $F_{1}$. These 18 generations are those given by Jinks and Perkins (1969) but exclude the $\mathrm{F}_{3}$ and first backcrosses selfed which cannot be obtained in sexually dimorphic species. Correlations between $h$ and $l$ and between $m$ and $i$ and $m$ and $h$ allow these four parameters to be written as two composite parameters $(m+h+l)$ and $(m+i)$. All the parameters are as given by Jinks and Perkins and are given as the simple parameters multiplied by increasing powers of $p$. The three right-hand columns of table 1 give the expectations of epistatic parameters if there is no linkage, i.e. interchromosomal interactions.

Although only 18 generations are listed, there are a total of 43 reciprocal crosses, frequently with different expectations. For instance, the second back-crosses each have four reciprocal crosses and three different expectations. In itself this situation provides a test for linked epistatic genes; if reciprocal crosses of the same generation have different means, linked epistatic genes must be present provided that sex-linkage, cytoplasmic and maternal influences have first been discounted by examination of the parental and $F_{1}$ generation means. This test will not detect unlinked epistatic genes and is applicable only where the recombination between genes differs in the two sexes. Only the parental $F_{1}, F_{2}$ and $F_{2}$ bip generations have no reciprocals or have reciprocal crosses with the same expectations, so the test may be applied to 13 generations. Comparison of table 1 with table 3 of Jinks and Perkins (1969) shows certain similarities. Thus the coefficients of $(m+h+l),(m+i), p^{2} i$ and $p^{2} l$ are invariably positive whilst those of $p i$ and $p l$ are always negative. The coefficients of $d, p j$ and $p^{2} j$ are positive and negative with equal frequency. Unlike Jinks and Perkins' model the $p^{4} l$ parameter is not required in table 1 and $p^{3} l$ is specified only three times. Further, the mean of $\mathrm{F}_{2}$ bip can be accurately specified whereas Jinks and Perkins equated the observed mean to the expected for that generation in order to avoid specifying three parameters; $p^{3} i, p^{5} l, p^{6} l$. This reflects the fewer opportunities for recombination when the male meiosis is achiasmate. 
TABLE 1

Model for first degree statistics specifying linked digenic interactions where recombination is confined to the female

(N.B. $-p i_{a b}$ is written as $p i$, etc.)

Inter-

chromosomal

parameters

Generation

$P_{1}$
$P_{2}$
$F_{1}$
$F_{2}$

$B_{1}\left\{\begin{array}{l}F_{1} \times P_{1} \\ P_{1} \times F_{1}\end{array}\right.$

$B_{2}\left\{\begin{array}{l}F_{1} \times P_{2} \\ P_{2} \times F_{1}\end{array}\right.$

$\left\{\begin{array}{l}F_{2} \times P_{1} \\ P_{1} \times F_{2}\end{array}\right.$

$\left\{\begin{array}{l}\mathrm{F}_{2} \times \mathrm{P}_{2} \\ \mathrm{P}_{2} \times \mathrm{F}_{2}\end{array}\right.$

$\left\{\begin{array}{l}\mathrm{F}_{1} \times \mathrm{F}_{2} \\ \mathrm{~F}_{2} \times \mathrm{F}_{1}\end{array}\right.$

bip $\mathrm{F}_{2} \times \mathrm{F}_{2}$

$B_{11}\left\{\begin{array}{l}\left(F_{1} \times P_{1}\right) \times P_{1} \\ \left(P_{1} \times F_{1}\right) \times P_{1} \\ P_{1} \times\left(F_{1} \times P_{1}\right) \\ P_{1} \times\left(P_{1} \times F_{1}\right)\end{array}\right.$

$B_{12}\left\{\begin{array}{l}\left(\mathrm{F}_{1} \times \mathrm{P}_{1}\right) \times \mathrm{P}_{2} \\ \left(\mathrm{P}_{1} \times \mathrm{F}_{1}\right) \times \mathrm{P}_{2} \\ \mathrm{P}_{2} \times\left(\mathrm{F}_{1} \times \mathrm{P}_{1}\right) \\ \mathrm{P}_{2} \times\left(\mathrm{P}_{1} \times \mathrm{F}_{1}\right)\end{array}\right.$

$\mathrm{B}_{22} \begin{cases}\left(\mathrm{~F}_{1} \times \mathrm{P}_{2}\right) \times \mathrm{P}_{2} & -\frac{3}{4} \\ \left(\mathrm{P}_{2} \times \mathrm{F}_{1}\right) \times \mathrm{P}_{2} & -\frac{3}{4} \\ \mathrm{P}_{2} \times\left(\mathrm{F}_{1} \times \mathrm{P}_{2}\right) & -\frac{3}{4} \\ \mathrm{P}_{2} \times\left(\mathrm{P}_{2} \times \mathrm{F}_{1}\right) & -\frac{3}{4}\end{cases}$

$\mathrm{B}_{21}\left\{\begin{array}{l}\left(\mathrm{F}_{1} \times \mathrm{P}_{2}\right) \times \mathrm{P}_{1} \\ \left(\mathrm{P}_{2} \times \mathrm{F}_{1}\right) \times \mathrm{P}_{1} \\ \mathrm{P}_{1} \times\left(\mathrm{F}_{1} \times \mathrm{P}_{2}\right) \\ \mathrm{P}_{1} \times\left(\mathrm{P}_{2} \times \mathrm{F}_{1}\right)\end{array}\right.$

$B_{1} \times F_{1}\left\{\begin{array}{l}\left(\mathrm{F}_{1} \times \mathrm{P}_{1}\right) \times \mathrm{F}_{1} \\ \left(\mathrm{P}_{1} \times \mathrm{F}_{1}\right) \times \mathrm{F}_{1} \\ \mathrm{~F}_{1} \times\left(\mathrm{F}_{1} \times \mathrm{P}_{1}\right) \\ \mathrm{F}_{1} \times\left(\mathrm{P}_{1} \times \mathrm{F}_{1}\right)\end{array}\right.$

$\mathrm{B}_{2} \times \mathrm{F}_{1} \begin{cases}\left(\mathrm{~F}_{1} \times \mathrm{P}_{2}\right) \times \mathrm{F}_{1} & -\frac{1}{4} \\ \left(\mathrm{P}_{2} \times \mathrm{F}_{1}\right) \times \mathrm{F}_{1} & -\frac{1}{4} \\ \mathrm{~F}_{1} \times\left(\mathrm{F}_{1} \times \mathrm{P}_{2}\right) & -\frac{1}{4} \\ \mathrm{~F}_{1} \times\left(\mathrm{P}_{2} \times \mathrm{F}_{1}\right) & -\frac{1}{4}\end{cases}$

$\mathrm{B}_{1} \operatorname{bip}\left\{\begin{array}{l}\left(\mathrm{F}_{1} \times \mathrm{P}_{1}\right) \times\left(\mathrm{F}_{1} \times \mathrm{P}_{1}\right) \\ \left(\mathrm{P}_{1} \times \mathrm{F}_{1}\right) \times\left(\mathrm{P}_{1} \times \mathrm{F}_{1}\right)\end{array}\right.$

$B_{2}$ bip $\begin{cases}\left(\mathrm{F}_{1} \times \mathrm{P}_{2}\right) \times\left(\mathrm{F}_{1} \times \mathrm{P}_{2}\right) & -\frac{1}{2} \\ \left(\mathrm{P}_{2} \times \mathrm{F}_{1}\right) \times\left(\mathrm{P}_{2} \times \mathrm{F}_{1}\right) & -\frac{1}{2}\end{cases}$

$-\frac{1}{2}$

$-\frac{1}{2}$
$-\frac{1}{2}$ $d \quad m+h+l m+i$ pi $p^{2} i \quad p j \quad p^{2} j \quad p l \quad p^{2} l \quad p^{3} l$

$\overbrace{i} \overbrace{j}$

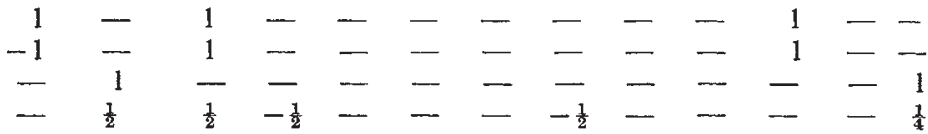

$\frac{1}{\frac{1}{2}}$

$\frac{1}{2}$

$-\frac{1}{2}=-\frac{1}{2}=-\frac{1}{2}=$

$\begin{array}{lll}\frac{1}{4} & \frac{1}{4} & \frac{1}{4} \\ \frac{1}{4} & \frac{1}{4} & \frac{1}{4}\end{array}$

$\frac{\frac{1}{2}}{\frac{1}{2}}-\frac{1}{2}=-\frac{1}{2}=-\frac{1}{2}=$ - $\frac{1}{4}-\frac{1}{4}$ - $^{\frac{1}{4}}$

$\frac{1}{2}$

$\begin{array}{llllllll}\frac{1}{2} & -\frac{1}{2} & \frac{1}{4} & \frac{1}{2} & -\frac{1}{4} & -\frac{1}{2} & \frac{1}{4} & - \\ \frac{1}{2} & -\frac{1}{4} & - & \frac{1}{4} & - & -1 & -1 & -1\end{array}$

$\begin{array}{lll}\frac{1}{4} & \frac{1}{4} & \frac{1}{4} \\ \frac{1}{4} & \frac{1}{4} & \frac{1}{4}\end{array}$

$\begin{array}{llllllll}\frac{1}{2} & -\frac{1}{2} & \frac{1}{4} & -\frac{1}{2} & \frac{1}{4} & -\frac{1}{2} & \frac{1}{4} & - \\ \frac{1}{2} & -\frac{1}{4} & - & -\frac{1}{4} & - & -\frac{1}{4} & - & -\end{array}$

$\begin{array}{llll}\frac{1}{4} & -1 & \frac{1}{4} & -1\end{array}$

$\frac{1}{2}-\frac{3}{4}--\quad-\quad \frac{3}{4} \frac{1}{2}--\frac{1}{4}$

$-\frac{1}{2}$

$\frac{1}{2}-\frac{1}{2} \frac{1}{4}-0-\frac{1}{2}-1 \frac{1}{4}$

$\frac{1}{2}-\frac{3}{4}-\begin{array}{lllll}\frac{3}{4} & -\frac{1}{4}-\frac{1}{4}\end{array}$

$-\frac{1}{2}$

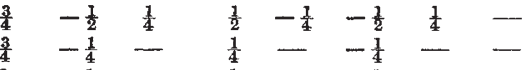

$-\frac{1}{4}-$

(1)

$\begin{array}{lllllll}-\frac{1}{2} & \frac{1}{1} & -\frac{1}{2} & \frac{1}{4} & -\frac{1}{2} & \frac{1}{2} & - \\ -1 & = & -\frac{1}{4} & - & 1 & - \\ -\frac{1}{4} & - & -\frac{1}{4} & - & -\frac{1}{4} & - & -\end{array}$

$\frac{1}{16}-\frac{3}{16} \frac{9}{16}$

$\frac{1}{16}-\frac{3}{16} \quad \frac{9}{16}$

$\frac{1}{16}-\frac{3}{16} \quad \frac{9}{16}$

$\frac{1}{16}-\frac{3}{16} \frac{9}{16}$

$\begin{array}{llllllllll}-\frac{1}{2} & \frac{1}{4} & -\frac{1}{2} & \frac{1}{4} & -\frac{1}{2} & \frac{1}{4} & - & \frac{9}{16} & -\frac{3}{16} & \frac{1}{16}\end{array}$

$-\frac{1}{1}-1-\frac{1}{1}-\frac{9}{16}-\frac{3}{16} \frac{1}{16}$

$-\frac{1}{4}--\frac{1}{4}--\frac{1}{4}--$

$\frac{9}{16}-\frac{3}{16} \quad \frac{1}{16}$

$\frac{9}{16}-\frac{3}{16} \frac{1}{16}$

$\begin{array}{llllllll}\frac{1}{4} & -\frac{1}{2} & \frac{1}{4} & \frac{1}{2} & -1 & -\frac{1}{2} & \frac{1}{4} & = \\ 4 & -\frac{1}{4} & - & \frac{1}{4} & - & -1 & -1 \\ 4 & -1 & - & \frac{1}{4} & - & -1 & - & -\end{array}$

$\frac{1}{16} \quad \frac{8}{16} \quad \frac{9}{16}$

$\frac{1}{16} \quad \frac{3}{16} \frac{9}{16}$

$\frac{3}{16} \frac{9}{16}$

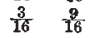

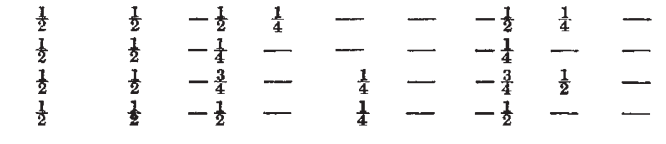

$\frac{1}{16} \quad \frac{1}{8} \quad \frac{1}{4}$

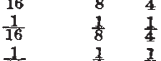

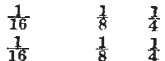

$\frac{1}{2}-\frac{1}{2} \frac{1}{4}-x^{\frac{1}{2}} \frac{1}{4}-\frac{1}{16}-\frac{1}{8} \frac{1}{4}$

$\frac{1}{2}-\frac{1}{4}----\frac{1}{4}-\frac{1}{16}-\frac{1}{8}$

$\frac{1}{2}-\frac{3}{2}--\frac{1}{2}--\frac{3}{2}-\frac{1}{2}-\frac{1}{16}-\frac{1}{1}$ $\frac{1}{2}$

$\begin{array}{lllllllll}\frac{3}{8} & \frac{5}{8} & -\frac{3}{4} & \frac{1}{4} & \frac{3}{8} & -\frac{1}{8} & -\frac{3}{4} & \frac{3}{4} & -\frac{1}{4} \\ \frac{3}{8} & \frac{5}{8} & -\frac{1}{4} & - & \frac{1}{8} & - & -4 & -\frac{1}{4} & -\end{array}$

$\frac{16}{16}-\frac{1}{8} \quad \frac{1}{4}$

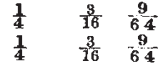

$\begin{array}{llllllll}\frac{5}{8} & -\frac{3}{4} & \frac{1}{4} & -\frac{3}{8} & \frac{1}{8} & -\frac{3}{4} & \frac{3}{4} & -\frac{2}{4} \\ \frac{5}{8} & -4 & - & -\frac{1}{8} & - & -1 & -1 & -1\end{array}$

$\begin{array}{lll}1 & -\frac{3}{16} & 9.9 \\ \frac{1}{4} & -\frac{3}{16} & \frac{9}{64}\end{array}$ 


\section{(ii) Scaling tests}

Van der Veen (1959) has given the expectations of the scaling tests of Mather (1949), Opsahl (1956) and his own $\mathrm{T}_{1}$ and $\mathrm{T}_{2}$ tests. These are reproduced in table 2 together with expectations of the second back-cross scaling tests of Hill (1966), but the notation of the parameters has been changed to coincide with that of Jinks and Perkins (1969). These expectations may be compared with those for Drosophila (or any other species in which recombination is restricted to the female), shown in table 3 . The greater number of tests is due to the reciprocal crosses having different expectations. Thus the $\mathrm{A}\left(\overline{\mathrm{P}}_{1}+\overline{\mathrm{F}}_{1}-2 \overline{\mathrm{B}}_{1}\right)$ and $\mathrm{B}\left(\overline{\mathrm{P}}_{2}+\overline{\mathrm{F}}_{1}-2 \overline{\mathrm{B}}_{2}\right)$ scaling tests each have two reciprocal crosses. In the first, where the back-cros ${ }_{\mathrm{S}}$

TABLE 2

Expectations of scaling tests for linked epistatic genes with recombination in both sexes (after van der Veen, 1959)

$\begin{array}{lcrrrrrr}\text { Test } & p i & p^{2} i & p j & p^{2} j & p l & p^{2} l & p^{3} l \\ \mathrm{~A} & 1 & - & -1 & - & 1 & - & - \\ \mathrm{B} & 1 & - & 1 & - & 1 & - & - \\ \mathrm{C} & 4 & - & - & - & 4 & -4 & - \\ \mathrm{O} & 1 & - & - & - & 1 & -3 & 2 \\ \mathrm{~T}_{1} & 1 & - & -\frac{1}{2} & - & 1 & -2 & 1 \\ \mathrm{~T}_{2} & 1 & - & -1 & - & 1 & -2 & 1 \\ \mathrm{~B}_{11} & 2 & -1 & -2 & 1 & 2 & -1 & - \\ \mathrm{B}_{12} & 2 & -1 & 2 & -1 & 2 & -1 & - \\ \mathrm{B}_{22} & 2 & -1 & 2 & -1 & 2 & -1 & - \\ \mathrm{B}_{21} & 2 & -1 & -2 & 1 & 2 & -1 & -\end{array}$

is made up using the $F_{1}$ as female $\left(F_{1} \times\right.$ Parent $)$ the expectation is identical to the usual case. Where the back-cross is made up using the $F_{1}$ as male (Parent $\times \mathrm{F}_{1}$ ), no epistasis resulting from linked genes would be detected. There is only one reciprocal cross for the $\mathrm{C}$ test $\left(\overline{\mathrm{P}}_{1}+\overline{\mathrm{P}}_{2}+2 \overline{\mathrm{F}}_{1}-4 \mathrm{~F}_{2}\right)$ in Drosophila. As in the conventional case (table 2), it detects $i$ and $l$ type interactions but is less powerful; the coefficients are only one-half those of the conventional case. Opsahl's 0 test $\left(\overline{\mathrm{F}}_{2} \times \mathrm{P}_{1}+\overline{\mathrm{F}}_{2} \times \mathrm{P}_{2}-\overline{2 \mathrm{~F}_{2} \times \mathrm{F}_{1}}\right)$ has two reciprocal crosses since the $\mathrm{F}_{2}$ may be used either as female (as shown) or male parent. In the former case no epistasis resulting from linked interacting genes would be detected. In the latter case the test measures $i$ and $l$ type epistasis, as in the conventional case, though the coefficients differ. Thus in the absence of effective linkage $(P=0 \cdot 5)$ the conventional case detects only additive $\times$ additive epistasis but in Drosophila $l$ type epistasis would still be detected. It must be remembered that, whereas in most species two genes do not show linkage if they are 50 (or more) map units apart on the same chromosome, in Drosophila two such genes are completely linked in the male and show free recombination only in the female. There are four possible reciprocal combinations of the $T_{1}\left(\bar{B}_{11}+\bar{B}_{12}-\overline{2 B_{1} \times F_{1}}\right)$ and $\mathrm{T}_{2}\left(\overline{\mathrm{B}}_{22}+\overline{\mathrm{B}}_{21}-\overline{\left.2 \mathrm{~B}_{2} \times \mathrm{F}_{1}\right)}\right.$ tests depending upon whether the first back-cross is used as male or female and upon which reciprocal of the first back-cross is used. In each of these two $T$ tests two reciprocals do not detect linked epistasis and two detect $i, j$ and $l$ type linked epistasis, as in the conventional case, though again the coefficients differ. There are also four reciprocals of the $\mathrm{B}_{11}\left(3 \overline{\mathrm{P}}_{1}+\overline{\mathrm{F}}_{1}-4 \overline{\mathrm{B}}_{11}\right), \mathrm{B}_{12}\left(\overline{\mathrm{P}}_{2}+3 \overline{\mathrm{F}}_{1}-4 \overline{\mathrm{B}}_{12}\right), \mathrm{B}_{22}\left(3 \overline{\mathrm{P}}_{2}+\overline{\mathrm{F}}_{1}-4 \overline{\mathrm{B}}_{22}\right)$ and 
$\mathrm{B}_{21}\left(\mathrm{P}_{1}+3 \mathrm{~F}_{1}-4 \overline{\mathrm{B}}_{21}\right)$ tests in Drosophila depending on which reciprocal of the second back-cross is used. One of each of these four tests does not detect linked epistasis and the remaining three detect $i, j$ and $l$ linked epistasis, though with different efficiencies. In the conventional case (table 2) all four tests detect $i, j$ and $l$ type epistasis.

TABLE 3

Expectations of scaling tests for linked epistatic genes when recombination is confined to the female

\begin{tabular}{|c|c|c|c|c|c|c|c|}
\hline & Test & $p i$ & $p^{2} i$ & $p j$ & $p^{2} j$ & $p l$ & $p^{2} l$ \\
\hline A & $\left(\mathrm{F}_{1} \times \mathrm{P}_{1}\right)$ & 1 & - & -1 & - & 1 & - \\
\hline A & $\left(\mathrm{P}_{1} \times \mathrm{F}_{1}\right)$ & - & - & - & - & - & -1 \\
\hline B & $\left(\mathrm{F}_{1} \times \mathrm{P}_{2}\right)$ & 1 & - & 1 & - & 1 & - \\
\hline B & $\left(\mathrm{P}_{2} \times \mathrm{F}_{1}\right)$ & - & - & - & - & - & 一 \\
\hline C & & 2 & - & - & - & 2 & - \\
\hline 0 & $\mathrm{~F}^{2}+$ & - & - & - & - & - & - \\
\hline 0 & $\mathrm{~F}_{2} \mathrm{\sigma}^{\star}$ & 1 & - & - & - & 1 & -1 \\
\hline $\mathrm{T}_{1} \mathrm{~B}_{1}$ 우 & $\left(\mathrm{F}_{1} \times \mathrm{P}_{1}\right)$ & - & - & 一 & - & - & - \\
\hline$T_{1} B_{1}$ 우 & $\left(P_{1} \times F_{1}\right)$ & - & - & - & - & 一 & - \\
\hline$T_{1} B_{10}$ & $\left(F_{1} \times P_{1}\right)$ & 1 & - & $-\frac{1}{2}$ & - & 1 & -1 \\
\hline $\mathrm{T}_{1} \mathrm{~B}_{1} \mathrm{O}^{*}$ & $\left(P_{1} \times F_{1}\right)$ & 1 & - & $-\frac{1}{2}$ & - & 1 & - \\
\hline $\mathrm{T}_{2} \mathrm{~B}_{2}$ ㅇ & $\left(\mathrm{F}_{1} \times \mathrm{P}_{2}\right)$ & - & - & - & - & - & - \\
\hline $\mathrm{T}_{2} \mathrm{~B}_{2}$ ㅇ & $\left(P_{2} \times F_{1}\right)$ & - & - & - & - & - & - \\
\hline $\mathrm{T}_{2} \quad \mathrm{~B}_{2} \mathrm{O}^{\star}$ & $\left(\mathrm{F}_{1} \times \mathrm{P}_{2}\right)$ & 1 & - & $\frac{1}{2}$ & - & 1 & -1 \\
\hline $\mathrm{T}_{2} \mathrm{~B}_{2} \mathrm{O}^{*}$ & $\left(\mathrm{P}_{2} \times \mathrm{F}_{1}\right)$ & 1 & - & $\frac{1}{2}$ & - & 1 & - \\
\hline$B_{11}$ & $\left(\mathrm{~F}_{1} \times \mathrm{P}_{1}\right) \times \mathrm{P}_{1}$ & 2 & -1 & -2 & 1 & 2 & -1 \\
\hline $\mathrm{B}_{11}$ & $\left(\mathrm{P}_{1} \times \mathrm{F}_{1}\right) \times \mathrm{P}_{1}$ & 1 & 一 & -1 & - & 1 & 一 \\
\hline$B_{11}$ & $\mathrm{P}_{1} \times\left(\mathrm{F}_{1} \times \mathrm{P}_{1}\right)$ & 1 & - & -1 & - & I & - \\
\hline$B_{11}$ & $\mathrm{P}_{1} \times\left(\mathrm{P}_{1} \times \mathrm{F}_{1}\right)$ & - & - & - & - & - & - \\
\hline $\mathrm{B}_{12}$ & $\left(F_{1} \times P_{1}\right) \times P_{2}$ & 2 & -1 & 2 & -1 & 2 & -1 \\
\hline $\mathrm{B}_{12}$ & $\left(\mathrm{P}_{1} \times \mathrm{F}_{1}\right) \times \mathrm{P}_{2}$ & 1 & - & 1 & - & 1 & 一 \\
\hline $\mathrm{B}_{12}$ & $\mathrm{P}_{2} \times\left(\mathrm{F}_{1} \times \mathrm{P}_{1}\right)$ & 1 & - & 1 & - & 1 & 一 \\
\hline $\mathrm{B}_{12}$ & $\mathrm{P}_{2} \times\left(\mathrm{P}_{1} \times \mathrm{F}_{1}\right)$ & 一 & - & - & - & - & - \\
\hline $\mathrm{B}_{22}$ & $\left(\mathrm{~F}_{1} \times \mathrm{P}_{2}\right) \times \mathrm{P}_{2}$ & 2 & -1 & 2 & -1 & 2 & -1 \\
\hline $\mathrm{B}_{22}$ & $\left(\mathrm{P}_{2} \times \mathrm{F}_{1}\right) \times \mathrm{P}_{2}$ & 1 & - & 1 & - & 1 & - \\
\hline $\mathrm{B}_{22}$ & $\mathrm{P}_{2} \times\left(\mathrm{F}_{1} \times \mathrm{P}_{2}\right)$ & 1 & - & 1 & - & 1 & - \\
\hline $\mathrm{B}_{22}$ & $\mathrm{P}_{2} \times\left(\mathrm{P}_{2} \times \mathrm{F}_{1}\right)$ & - & - & - & 一 & - & - \\
\hline $\mathrm{B}_{21}$ & $\left(\mathrm{~F}_{1} \times \mathrm{P}_{2}\right) \times \mathrm{P}_{1}$ & 2 & -1 & -2 & 1 & 2 & -1 \\
\hline $\mathrm{B}_{21}$ & $\left(\mathrm{P}_{2} \times \mathrm{F}_{1}\right) \times \mathrm{P}_{1}$ & - & - & - & - & - & - \\
\hline $\mathrm{B}_{21}$ & $\mathrm{P}_{1} \times\left(\mathrm{F}_{1} \times \mathrm{P}_{2}\right)$ & 1 & - & -1 & - & 1 & - \\
\hline$B_{21}$ & $P_{1} \times\left(P_{2} \times F_{1}\right)$ & - & - & 一 & - & - & - \\
\hline
\end{tabular}

Table 3 does not cover every possibility. For instance the A test could be constructed using each reciprocal of the first back-cross once

$$
\text { (i.e. } \left.\overline{\mathrm{P}}_{1}+\overline{\mathrm{F}}_{1}-\overline{\left(\mathrm{P}_{1} \times \mathrm{F}_{1}\right.}\right)-\left(\overline{\left.\mathrm{F}_{1} \times \mathrm{P}_{1}\right)}\right) \text {. }
$$

In this case the expectation is $\frac{1}{2} p i-\frac{1}{2} p j+\frac{1}{2} p l$ which is the mean of the two A tests given in table 3 . The same holds for the B test. This principle may be extended. The second back-cross tests may be constructed using each of the four reciprocals of the second back-cross once. For the $B_{11}$ test the expectation becomes $p i-\frac{1}{4} p^{2} i-p j+\frac{1}{4} p^{2} j+p l-\frac{1}{4} p^{2} l$, which is the mean of the four $B_{11}$ tests shown in table 3 . The same holds for the $B_{12}, B_{22}$ and $\mathrm{B}_{21}$ tests. A considerable advantage accrues from keeping the reciprocal crosses separate. The expectations given on the left of table 1 are applicable to linked genes only and do not apply to interactions between unlinked 
genes, i.e. genes on separate chromosomes. The expectations for interactions between such unlinked genes are the same for those in a species having equal recombination in both sexes for the case where $p=0 \cdot 5$. They may be obtained from table 2 by putting $p=0.5$ and are given on the right of table 1. These expectations do not differ between reciprocal crosses. Thus keeping the reciprocal crosses separate enables linked interacting genes to be distinguished from unlinked interacting genes. As an example consider the A scaling test. Using the $\left(F_{1} \times \mathrm{P}_{1}\right)$ reciprocal of the first back-cross, the expectation is $p i-p j-p l$ for linked genes and $\frac{1}{2} i-\frac{1}{2} j+\frac{1}{2} l$ for unlinked genes. Using the $\left(\mathrm{P}_{1} \times \mathrm{F}_{1}\right)$ first back-cross reciprocal, the $\mathrm{A}$ scaling test expectation is $\frac{1}{2} i-\frac{1}{2} j+\frac{1}{2} l$ for the unlinked genes, the expectation for linked genes being zero. The value of the A scaling test using the $\left(\mathrm{P}_{1} \times \mathrm{F}_{1}\right)$ reciprocal is due to unlinked gene epistasis only. The excess over this value of the $A$ scaling test using the $\left(\mathrm{F}_{1} \times \mathrm{P}_{1}\right)$ reciprocal is due to epistasis between linked genes. The same principle may be applied to all the scaling tests with the exception of the $\mathrm{G}$ scaling test, for which only one reciprocal exists.

Van der Veen (1959) also considers various combinations of the scaling tests shown in tables 2 and 3 , such as $A+B, 2(A+B)-C$ and $T_{1}-T_{2}$. Glearly in Drosophila there will be a large number of such combinations depending on which reciprocals are chosen. The purpose is to detect specific interactions. For example $\mathrm{A}-\mathrm{B}$ measures only $j$ type interactions. However, the standard error of such combinations is always large and hence the power of the test is reduced. Individual parameters are best estimated by the method of Cavalli (1952) or directly from the unweighted generation means described below.

\section{(iii) Estimation of parameters}

The six parameters, $m, d, h, i, j$ and $l$ may be estimated directly from generation means by least squares (Cavalli, 1952), the generation means being weighted by the inverse of their variances. Scoring parents, $F_{1}, F_{2}$ and back-crosses the estimators are:

$$
\begin{aligned}
m & =\frac{1}{2}\left(\overline{\mathrm{P}}_{1}+\overline{\mathrm{P}}_{2}\right)-2\left(\overline{\mathrm{B}}_{1}+\overline{\mathrm{B}}_{2}\right)+4 \overline{\mathrm{F}}_{2} \\
d & =\frac{1}{2}\left(\overline{\mathrm{P}}_{1}-\overline{\mathrm{P}}_{2}\right) \\
h & =6\left(\overline{\mathrm{B}}_{1}+\overline{\mathrm{B}}_{2}\right)-\frac{3}{2}\left(\overline{\mathrm{P}}_{1}+\overline{\mathrm{P}}_{2}\right)-8 \overline{\mathrm{F}}_{2}-\overline{\mathrm{F}}_{1} \\
i & =2\left(\overline{\mathrm{B}}_{1}+\overline{\mathrm{B}}_{2}\right)-4 \overline{\mathrm{F}}_{2} \\
j & =2\left(\overline{\mathrm{B}}_{1}-\overline{\mathrm{B}}_{2}\right)-\overline{\mathrm{P}}_{1}+\overline{\mathrm{P}}_{2} \\
l & =\overline{\mathrm{P}}_{1}+\overline{\mathrm{P}}_{2}+2 \overline{\mathrm{F}}_{1}+4\left(\overline{\mathrm{F}}_{2}-\overline{\mathrm{B}}_{1}-\overline{\mathrm{B}}_{2}\right) .
\end{aligned}
$$

Where the genes are linked, however, the parameters become confounded. Van der Veen gives the expectations for linked genes in his table 4 for the case of recombination in both sexes. This is reproduced in table 4, though using the notation of this paper, together with the expectations for species where recombination occurs only in the female (e.g. Drosophila) which have been derived from table 1 . In this case the reciprocals have been used equally. Thus $i$ is estimated as

$$
\left(\mathrm{F}_{1} \times \mathrm{P}_{1}\right)+\left(\mathrm{P}_{1} \times \mathrm{F}_{1}\right)-\left(\mathrm{F}_{1} \times \mathrm{P}_{2}\right)-\left(\mathrm{P}_{2} \times \mathrm{F}_{1}\right)-4 \mathrm{~F}_{2}
$$

It will be noted from the upper part of table 4 , showing the conventional 
case of species with equal recombination in both sexes, that if $p$ is given a value of 0.5 (i.e. free recombination) the confounded parameters simplify to the unconfounded ones they represent. This is not the case in Drosophila (lower part of table 4) though the influence of $i$ on the estimates of $m$ and $h$ diminishes as $p$ increases. Hence the distortion of these two estimates by additive $\times$ additive type epistasis is at a minimum when $p=0.5$. It will be seen that in Drosophila the estimate of $l$ is zero if the interacting genes are linked. As with the scaling tests, if the genes are unlinked (i.e. on separate chromosomes) the parameters estimated will be those in the upper half of table 4 with $p=0 \cdot 5$. That is, no distortion results except if the

TABLE 4

Estimates of parameters when confounded by linkage

Parameters actually estimated

Estimate

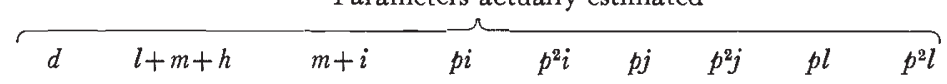

Usual case

$\begin{array}{llllllllll}m & - & - & 1 & -2 & - & - & - & -2 & 4 \\ d & 1 & - & - & - & - & - & - & - & - \\ h & - & 1 & -1 & 2 & - & - & - & 2 & -8 \\ i & - & - & - & 2 & - & - & - & 2 & -4 \\ j & - & - & - & - & - & 2 & - & - & - \\ l & - & - & - & - & - & - & - & - & 4\end{array}$

Drosophila

\begin{tabular}{|c|c|c|c|c|c|c|c|c|c|}
\hline$m$ & - & - & 1 & -1 & - & - & - & -1 & - \\
\hline$d$ & 1 & - & - & - & - & - & - & - & - \\
\hline$h$ & - & 1 & -1 & 1 & - & - & - & 1 & - \\
\hline$i$ & - & - & - & 1 & - & - & - & 1 & - \\
\hline$j$ & - & - & - & - & - & 1 & - & - & - \\
\hline$l$ & - & - & - & - & - & - & - & - & - \\
\hline
\end{tabular}

interacting genes are on the same chromosome even if they are 50 map units apart on that chromosome. Since there are only four chromosomes in Drosophila, one of which is very small, it may be expected that interacting genes will frequently be on the same chromosome and in consequence the distortion may be considerable.

\section{Discussion}

The expectations presented in this paper provide a theoretical basis for the analysis of epistasis in species in which recombination is restricted to the female, of which Drosophila is the most obvious example. By using appropriate combinations of reciprocal crosses it is possible to distinguish between epistasis resulting from interactions between genes located on the same chromosome and that resulting from interactions between genes on different chromosomes, and to estimate the relative magnitudes of both types. The simplicity of this method contrasts with that where recombination occurs in both males and females. The technique developed by Jinks and Perkins (1969) is to fit a model which includes unlinked digenic epistatic parameters by least squares. The adequacy of this model may be tested by a $\chi^{2}$. Should the $\chi^{2}$ be significant (i.e. the model is inadequate), a second model involving linkage is fitted to see if the fit can be improved. 
If linkage is important, the parameters having higher powers of $p, e . g$. $p^{2} i, p^{2} l$, will be significant. Unfortunately the only comparison between the adequacy of the model excluding linkage and that including linkage is the relative sizes of the two $\chi^{2}$, whereas in Drosophila the scaling tests can yield two values; one for measuring unlinked gene interaction and one measuring linked gene interaction, and direct comparison is possible. There is, however, an important limitation to the method. Since the proposed analysis rests on comparing the means of reciprocal crosses, any factor which might cause conventional reciprocal differences must be eliminated. This includes sex-linkage and cytoplasmic effects, though the problem of sexlinkage can be overcome by a method suggested by $\operatorname{Dr} \mathrm{M}$. J. Kearsey. This is to construct chromosome substitution lines which differ in their autosomes but are isogenic for the sex-chromosomes. Crosses between such lines will show autosomal segregation only.

If the scaling tests are used to determine the relative amounts of epistasis caused by interactions between linked and unlinked genes, an indication will be gained as to how much distortion caused by linkage can be expected in the estimates of first-degree parameters. Neither $d$ nor $j$ are confounded with any other parameter and $m$ is usually of little interest. The chief concern is that the dominance $\times$ dominance interactions of linked genes enter the dominance parameter, so that $h$ is bound to be large and $l$ is bound to be zero. This will have very serious implications for the interpretation of heterosis in Drosophila for what appears to be overdominance may well be epistasis, even if the dispersion of genes has been shown to be of no importance (i.e. $r \rightarrow 1$ ) (Jinks and Jones, 1958).

\section{SUMmaRY}

1. The expectations of 18 generation means derived from a cross between two inbred lines are given, assuming a model including linked digenic interactions with genic recombination occurring only at female gametogenesis.

2. Differences between the means of reciprocal crosses can be due to linked gene interactions but not unlinked gene interactions.

3. Using the same model, the expectations of scaling tests are given. It is possible to assess the relative proportions of epistasis attributable to unlinked genes and to linked genes by using different reciprocal crosses.

4. The bias caused by linkage to estimates of first-degree parameters is described; the distortion may prejudice the interpretation of heterosis.

Acknowledgments. - I am indebted to Dr M. J. Kearsey for his advice and encouragement throughout the course of this work, which was undertaken whilst in receipt of a Science Research Council Studentship.

\section{REFERENGES}

CAVALLI, L. L. 1952. An analysis of linkage in quantitative inheritance. Quantitative Inheritance, pp. 135-144. H.M.S.O.

HILL, J. 1966. Recurrent backcrossing in the study of quantitative inheritance. Heredity, $21,85-120$.

JINKS, J. L., AND JONES, R. MORLEY. 1958. Estimation of the components of heterosis. Genetics, 43, 223-234. 
JINKS, J. L., AND PERKINS, J. M. 1969. The detection of linked epistatic genes for a metrical trait. Heredity, 24, 465-475.

Mather, K. 1949. Biometrical Genetics. Methuen, London.

OPSAHL, B. 1956. The discrimination of interaction and linkage in continuous variation. Biometrics, 12, 415-432.

VAN DER VEEN, J. H. 1959. Tests of non-allelic interaction and linkage for quantitative characters in generations derived from two diploid pure lines. Genetica, 30, 201-232. 